NASA/TM-1999-209820

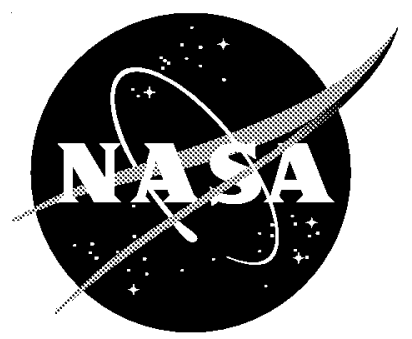

\title{
Uniaxial Stretching of Poly(keto-ether-imide)
} Films

Jeffrey A. Hinkley and James F. Dezern

Langley Research Center, Hampton, Virginia

L. Feuz

ETH, Zurich, Switzerland

D. Klinedinst

Norfolk State University, Norfolk, Virginia 


\section{The NASA STI Program Office ... in Profile}

Since its founding, NASA has been dedicated to the advancement of aeronautics and space science. The NASA Scientific and Technical Information (STI) Program Office plays a key part in helping NASA maintain this important role.

The NASA STI Program Office is operated by Langley Research Center, the lead center for NASA's scientific and technical information. The NASA STI Program Office provides access to the NASA STI Database, the largest collection of aeronautical and space science STI in the world. The Program Office is also NASA's institutional mechanism for disseminating the results of its research and development activities. These results are published by NASA in the NASA STI Report Series, which includes the following report types:

- TECHNICAL PUBLICATION. Reports of completed research or a major significant phase of research that present the results of NASA programs and include extensive data or theoretical analysis. Includes compilations of significant scientific and technical data and information deemed to be of continuing reference value. NASA counterpart of peer-reviewed formal professional papers, but having less stringent limitations on manuscript length and extent of graphic presentations.

- TECHNICAL MEMORANDUM. Scientific and technical findings that are preliminary or of specialized interest, e.g., quick release reports, working papers, and bibliographies that contain minimal annotation. Does not contain extensive analysis.

- CONTRACTOR REPORT. Scientific and technical findings by NASA-sponsored contractors and grantees.
- CONFERENCE PUBLICATION. Collected papers from scientific and technical conferences, symposia, seminars, or other meetings sponsored or co-sponsored by NASA.

- SPECIAL PUBLICATION. Scientific, technical, or historical information from NASA programs, projects, and missions, often concerned with subjects having substantial public interest.

- TECHNICAL TRANSLATION. Englishlanguage translations of foreign scientific and technical material pertinent to NASA's mission.

Specialized services that complement the STI Program Office's diverse offerings include creating custom thesauri, building customized databases, organizing and publishing research results ... even providing videos.

For more information about the NASA STI Program Office, see the following:

- Access the NASA STI Program Home Page at http://www.sti.nasa.gov

- E-mail your question via the Internet to help@sti.nasa.gov

- Fax your question to the NASA STI Help Desk at (301) 621-0134

- Phone the NASA STI Help Desk at (301) 621-0390

- Write to: NASA STI Help Desk NASA Center for AeroSpace Information 7121 Standard Drive Hanover, MD 21076-1320 
NASA/TM-1999-209820

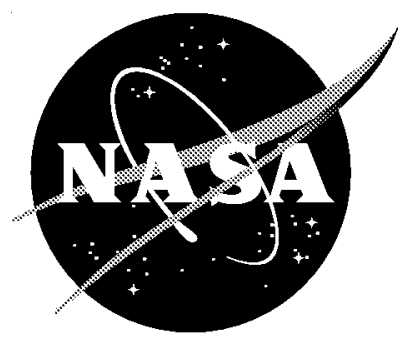

\section{Uniaxial Stretching of Poly(keto-ether-imide)}

Films

Jeffrey A. Hinkley and James F. Dezern

Langley Research Center, Hampton, Virginia

L. Feuz

ETH, Zurich, Switzerland

D. Klinedinst

Norfolk State University, Norfolk, Virginia

National Aeronautics and

Space Administration

Langley Research Center

Hampton, Virginia 23681-2199 
The use of trademarks or names of manufacturers in the report is for accurate reporting and does not constitute an official endorsement, either expressed or implied, of such products or manufacturers by the National Aeronautics and Space Administration.

Available from:

NASA Center for AeroSpace Information (CASI)

7121 Standard Drive

Hanover, MD 21076-1320

(301) 621-0390
National Technical Information Service (NTIS) 5285 Port Royal Road

Springfield, VA 22161-2171

(703) 605-6000 


\title{
Uniaxial Stretching of Poly(keto-ether-imide) Films
}

J. A. Hinkley and J. F. Dezern,

NASA Langley Research Center

\author{
L. Feuz, \\ ETH Zurich \\ and \\ D. Klinedinst \\ Norfolk State University
}

\begin{abstract}
$\underline{\text { Abstract }}$
Fully-cured aromatic polyimides were prepared from various combinations of five dianhydrides and six diamines. When heated progressively under constant load, most of the films elongated rapidly near their glass transition temperatures. In about half of the nineteen materials, the strain was self-limiting - a possible indication of straininduced crystallinity. The presence of crystallinity was established unambiguously for one material.
\end{abstract}




\section{$\underline{\text { Introduction }}$}

Polyimide films are durable, radiation-resistant materials that are useful as electrical insulation, in thermal blankets, as windows and barrier films, as supports in structures such as deployable solar arrays, and potentially, in solar sails and large inflatable platforms or reflectors. It is of interest to try to orient polyimides because the stiffness, strength and dimensional stability of most glassy or crystallizable polymers can be improved by stretch-orientation. In fact, commercial films such as Kapton® (DuPont) and Upilex ${ }^{\mathrm{TM}}$ (Ube) are probably biaxially oriented.

Stretching is also commonly used to improve piezoelectric and photorefractive materials. As polyimides are considered for these applications, it will be useful to understand how they respond to stretching.

The two-step synthesis of polyimides ${ }^{1}$ provides two opportunities to introduce orientation. First, the soluble amic acid precursor may be stretched. It may be possible to maintain or enhance the orientation as the succeeding imidization reaction is carried out thermally or chemically. This approach has been used both with fibers ${ }^{2}$ and with films. ${ }^{3}$ A disadvantage is the difficulty of managing a stretching process that is coupled with simultaneous solvent outgassing and a high-temperature curing reaction.

A second and potentially simpler alternative is to stretch the fully-imidized material. ${ }^{4}$ This requires that the polymer in question behave as a thermoplastic; fortunately, many such materials have been discovered. In the present feasibility study, 19 different fullycured polyimides were screened using thermal deformation analysis (TDA). The TDA technique, which involves heating to progressively higher temperatures under a constant load, has been useful in the qualitative study of stretch-induced crystallization. ${ }^{5}$

\section{Experimental}

Each polyimide was prepared from stoichiometric amounts of purified diamine and dianhydride. ${ }^{6}$ Acronyms are summarized in Table 1. 


\section{Table 1. Polyimide Monomers}

Dianhydrides




Diamines

Films were cast on soda-lime glass plates, dried in a reduced-humidity enclosure at room temperature, and cured in air-circulating ovens at $100^{\circ}, 200^{\circ}$ and $300^{\circ} \mathrm{C}$ successively, holding for 1 hour at each temperature.

A density gradient column was prepared from aqueous sodium bromide with 2propanol as a wetting agent.

The thermal deformation apparatus ${ }^{7}$ is shown schematically in Figure 1. The film sample was gripped by stainless-steel clamps that were tightened using screws. To prevent slipping and to help prevent film tearing at the grip, a piece of compliant quartz felt was placed between the film and the clamping strip. The initial specimen dimensions between clamps were 13 wide $\times 20 \mathrm{~mm}$ long. 
Dead-weight loading was applied via a chain attached to a swivel and a wire that ran over two pulleys to a long-stroke DC displacement transducer. Nominal stress in all cases was $7.0 \pm 1.8 \mathrm{MPa}$.

After the weight was applied, the displacement readout was zeroed at room temperature and the oven temperature was ramped to $350^{\circ} \mathrm{C}$. The initial ramp rate was $10^{\circ} \mathrm{C} / \mathrm{min}$., but above $200^{\circ} \mathrm{C}$ the oven could only maintain about $4.5^{\circ} \mathrm{C} / \mathrm{min}$. Noticeable stretching began 18 to 58 minutes into the TDA experiment, depending on the polymer. With this experimental approach, both the strain rate and the ultimate strain are determined by the material behavior rather than being controlled by the apparatus.

\section{$\underline{\text { Results and Discussion }}$}

The TDA traces are assembled in Figs. 2-6. Three distinct regions are evident in the sigmoidal curves. The first region is below the softening point, where very little strain occured. Then, most samples elongated fairly rapidly over a range of approximately $20^{\circ} \mathrm{C}$ beginning near the glass transition temperature. If the sample did not break at this point, there followed a range of temperatures over which the strain rate was very small again. This plateau at longer times, when it was seen in other polymers, has been attributed ${ }^{8,9}$ to strain-induced crystallization.

Although property improvements can be obtained by stretching materials that do not crystallize, ${ }^{10}$ crystallization can be helpful. The nascent crystals can serve as physical crosslinks, preventing stress relaxation during the stretching process and allowing a greater degree of orientation to be produced. In addition, crystallizing films can be annealed under stress ("heat set") to stabilize them against relaxation and shrinkage near the glass transition temperature. This raises their use temperatures relative to amorphous materials.

Many thermoplastic polyimides form metastable crystals during solution imidization ${ }^{11}$ but with the exception of very rigid or rod-like chains ${ }^{3,12}$, they do not usually crystallize spontaneously upon cooling from the melt. ${ }^{13}$ It is remarkable, therefore, that of the 19 materials in the present screening study, several became cloudy and 10 exhibited welldefined plateaux in the TDA experiment. Strain-induced crystallization could thus be a very general route to improved properties in aromatic polyimides.

The theory of simultaneous stretching and crystallization is not well developed; most treatments rely heavily on simplifying assumptions. ${ }^{14}$ There is even disagreement on whether the enhanced rate of crystallization arises primarily from nucleation or crystal growth. ${ }^{15,16}$ It is clear, however, that the degree of orientation created in the amorphous polymer is a key variable.

With this in mind, it appears that among the polymers studied here, those that contain the 3,3'- diamines may have melt viscosities too low to allow efficient orientation. They tend to stretch rapidly and break under constant load. At the other extreme was the 4, $4^{\prime}$-DABP/BPDA, which did not stretch appreciably at all even though the starting film is clear and flexible, with a $\mathrm{Tg}$ of $302^{\circ} \mathrm{C}$. In between, we find for example the polymers containing 3,4'-ODA. These readily strain-harden, which makes them rather forgiving in terms of processing. Although the details of the TDA responses of the individual 
polymers may depend somewhat on molecular weight, all the samples in the present study were prepared at the highest molecular weight practical, so it is believed that qualitative comparisons between materials should be valid.

In the discussion above, cloudiness and the leveling-off strain in the TDA experiment were taken as evidence for crystallization. Neither, of course, is definitive. Cloudiness would ordinarily imply the presence of crystallites or voids that are large enough to scatter visible light. In the present experiments stretching also produced a surface roughening, perhaps by accentuating the texture on the surface of the as-cast film. One side of the film remained shiny, however, and was quite featureless in the scanning electron microscope at 1000X. It is not known whether the air side or the side that had been cast against the glass plate became roughened, but the scattering was sufficient to thwart attempts to measure birefringence with prism-coupled or Abbe refractometers. Some of the films appeared to have a sheen that might be produced by light interacting with crazes.

Figure 7 is a differential scanning calorimetry scan of one of the materials that may have crystallized, 3,4-ODA/ODPA. This particular specimen was stretched isothermally at $260^{\circ} \mathrm{C}$. There is a melting peak near $320^{\circ} \mathrm{C}$, with a total melting endotherm of $21 \mathrm{~J} / \mathrm{g}$. Although the heat of fusion of this polymer is not known, comparison can be made with

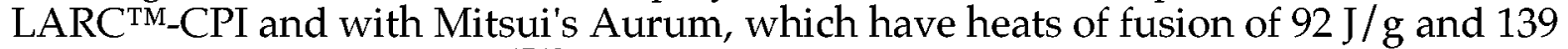
$\mathrm{J} / \mathrm{g}$ of crystals respectively. ${ }^{17,18}$ By this estimate, then, the crystallinity of the stretched $3,4^{\prime}$-ODA/ODPA may be as high as $20 \%$. The shape of the DSC curve suggests, however, that there may have been some "cold crystallization" between the $\mathrm{Tg}$ (ca. $230^{\circ} \mathrm{C}$ ) and the onset of melting. If a stretched sample is annealed for $30 \mathrm{~min}$ at $260^{\circ} \mathrm{C}$, it exhibits two endotherms, one at $320^{\circ} \mathrm{C}$ and a much smaller one with a peak at $275^{\circ} \mathrm{C}$. The total heat of melting for the two populations of crystals is $\sim 22 \mathrm{~J} / \mathrm{g}$ of polymer.

Density is often another useful indicator of crystallinity. Accordingly, stretched and unstretched 3,4'-ODA/ODPA films were compared. Although the oriented film had a tensile modulus in the stretch direction over twice as high as that of an unstretched film, its density $\left(1.3950 \mathrm{~g} / \mathrm{cm}^{3}\right)$ was only $1.1 \%$ higher. Given that the crystal density could be expected to be $13 \%$ higher than that of the completely amorphous polymer ${ }^{19}$, and assuming that there are no unwetted voids, $8 \%$ crystallinity would be inferred for this specimen.

Finally, it is known ${ }^{4}$ that when 3,4'-ODA/ODPA is stretched isothermally just above $\mathrm{Tg}$, it undergoes strain-induced crystallization when the strain exceeds approximately 2.5 . The X-ray diffraction pattern ${ }^{20}$ in Figure 8 shows conclusively that 3,4'-ODA/ODPA films stretched isothermally to a strain of 5 are crystalline, with a fiber repeat distance of $20.8 \AA$. A systematic search ${ }^{21}$ for extended conformations of this polymer readily finds several with a repeat unit end-to-end length of $20.2 \AA$ and an angular mismatch of only $4^{\circ}$; minor adjustments to bond angles and torsions would easily bring this prediction into agreement with experiment.

It seems likely that other polymers among those studied will crystallize well under suitable stretching conditions. TDA provides very useful guidance as a starting point for further (e.g. isothermal) stretching experiments. 


\section{Conclusions}

TDA is a useful screening tool for stretch-orientation. With it, 10 candidates for further optimization were identified. Structural requirements for successful crystallization appear to include both a relatively compact molecular conformation and a high enough melt viscosity just above $\mathrm{Tg}$ to sustain a fairly high degree of orientation.

\section{$\underline{\text { References }}$}

1. C. E. Sroog, Chapter 9 in Polymides, D. Wilson, H. D. Stenzenberger, and P. M. Hergenrother, eds., Chapman and Hall, NY, 1990.

2. For a review, see C. E. Sroog., Prog. Polym. Sci. 16, 561 (1991).

3. M. Kochi, T. Yonezawa, R. Yokota, and I. Mita, in Advances in Polyimide Science and Technology Proc. $4^{\text {th }}$ Int'l. Conf. On Polyimides, C. Feger, M. M. Khojasteh, and M. S. Htoo, eds., Technomic Publ., Lancaster, PA, 1993.

4. K. D. Dorsey, A. S. Abhiraman, J. A. Hinkley, and T. L. St. Clair, J. Appl. Polym. Sci., 73, 1215 (1999).

5. P. Desai and A. S. Abhiraman, J. Polym. Sci. (Phys) 26, 1675 (1988).

6. J. F.Dezern, and C. I. Croall, "Structure-Property Study of Keto-Ether Polyimides," in Advances in Polyimide Science and Technology Proc. $4^{\text {th }}$ Int'l 1 . Conf. On Polyimides, C. Feger, M. M. Khojasteh, and M. S. Htoo, eds, Technomic Publ., Lancaster, PA, 1993, p. 468.

7. D. Klinedinst, M. S. Thesis, Center for Materials Research, Norfolk State University, 1998.

8. G. L. Bourvellec, J. Beautemps, and J. P. Jerry, J. Appl. Polym. Sci. 39, 319 (1990).

9. D. R. Salem, Polymer 35(4), 771 (1994).

10. C. Fay, D. M. Stoakley, and A. K. St. Clair, Proc. 43rd Int'l SAMPE Symp. and Exhibition 43, 1178 (1998).

11. e.g. T. H. Hou, and J. M. Bai, High Performance Polymers 1(3), 191 (1989).

12. Polyimides-Thermally Stable Polymers, M. I. Bessonov, M. M. Koton, V.V. Kudryavtsev, and L. A. Laius, Consultants Bureau, NY, 1987, p. 207.

13. J. T. Mullerleile, B. G. Risch, D. E. Rodrigues, and G. L. Wilkes, Polymer 34(4), 789 (1993).

14. A. Ziabicki, L. Jarecki, and A. Wasiak, Comput. and Theor. Polymer Science 8(1/2), 143 (1998).

15. P. Desai and A. S. Abhiraman, J. Polym. Sci. Phys. 27, 2469 (1989).

16. E. H. Andrews, Proc. Roy. Soc. Lond. A277, 562 (1964).

17. D. C. Rich, P. P. Huo, C. Liu and P. Cebe, Proc. ACS Div. of Polymeric Matls. 68, 124 (1993).

18. J. B. Friler and P. Cebe, Polymer Engineering Science 33(10) 587 (1993).

19. M. V. Brillhart, Y. Y. Cheng, P.Nagarkar and P. Cebe, Polymer 38(12), 3059 (1997).

20. B. Farmer, Air Force Materials Laboratory, personal communication

21. R. K. Kincaid, A. D. Martin, and J. A. Hinkley, Computational Polymer Science 5, 1 (1995). 


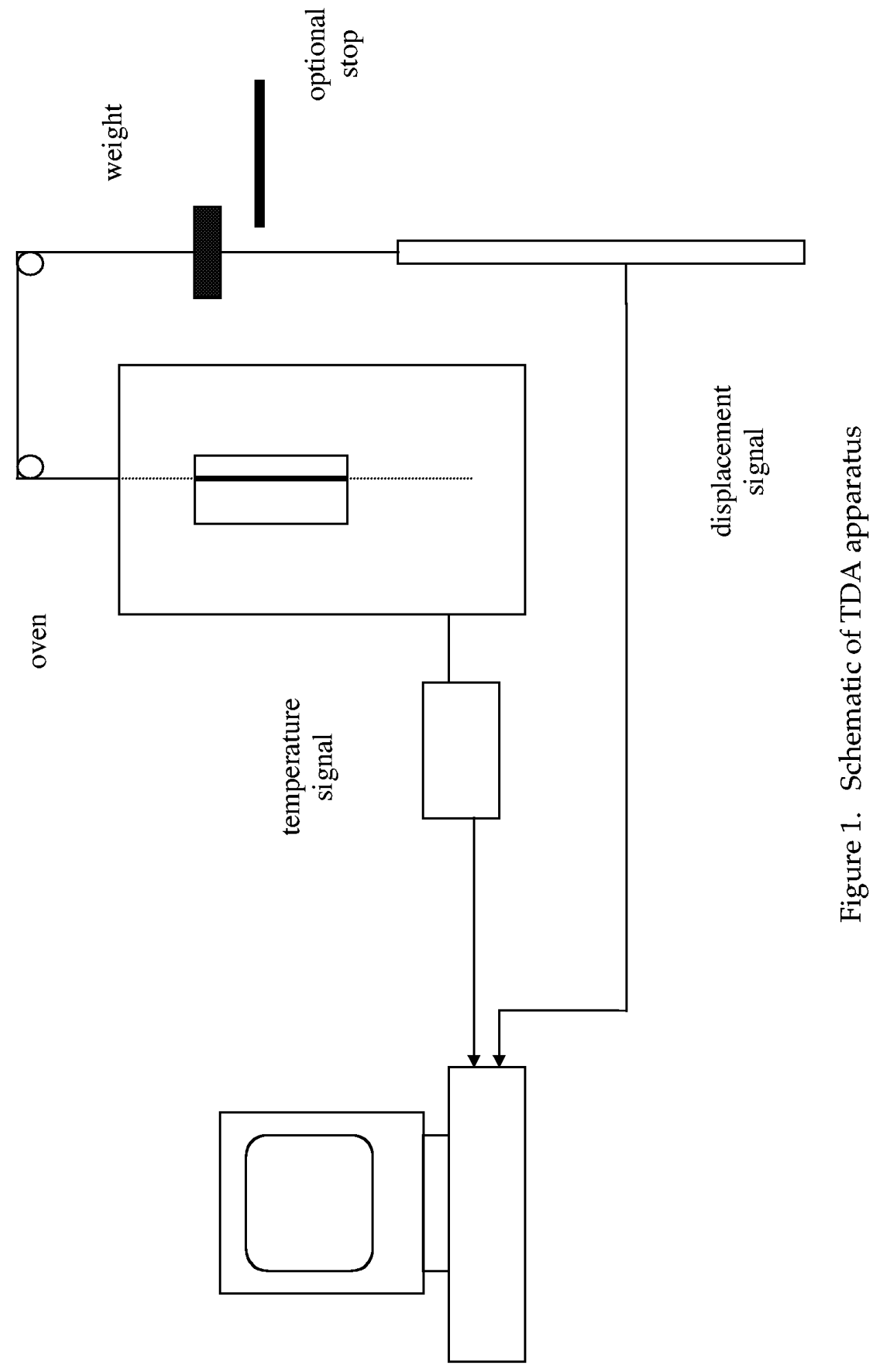




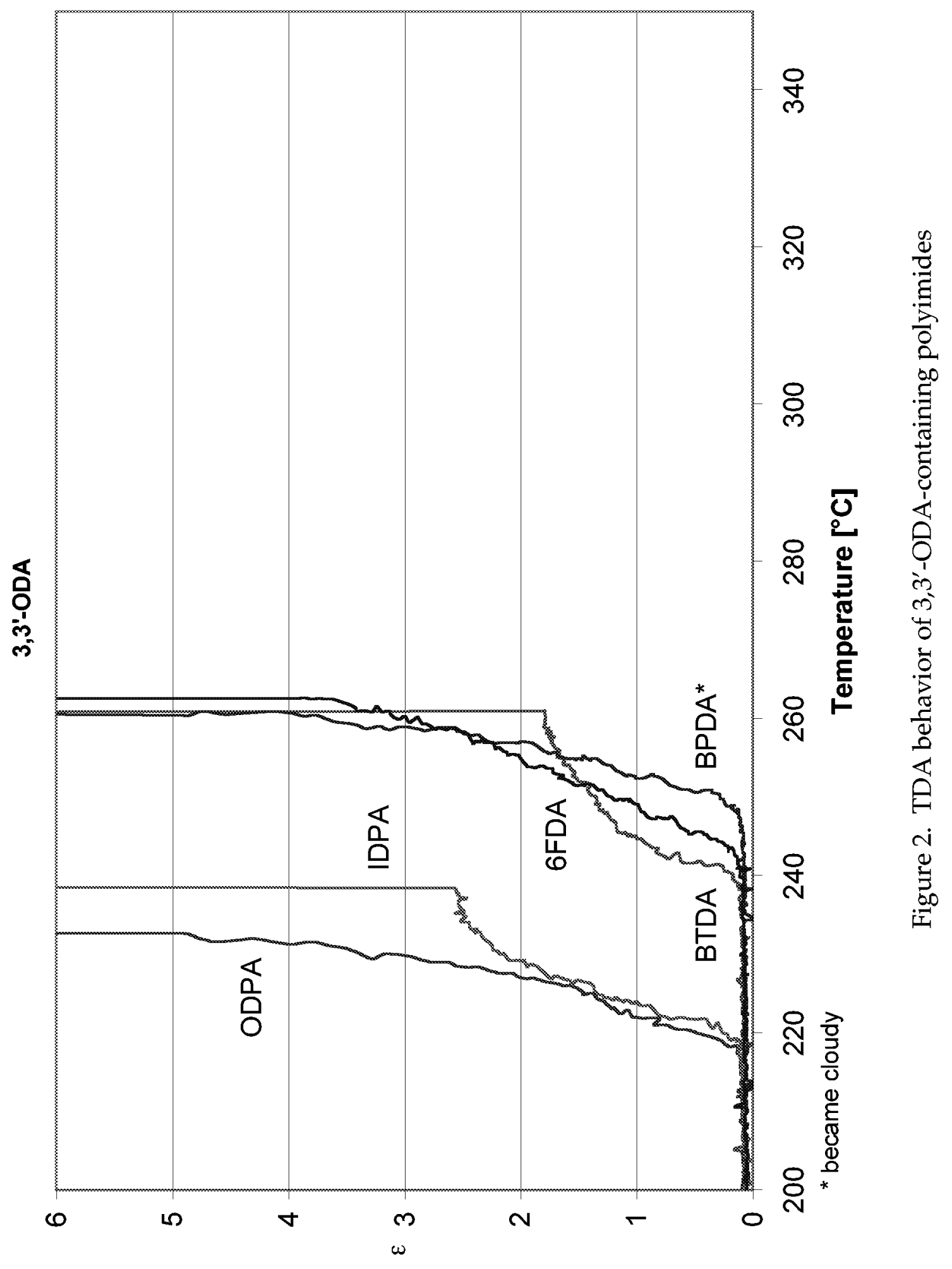




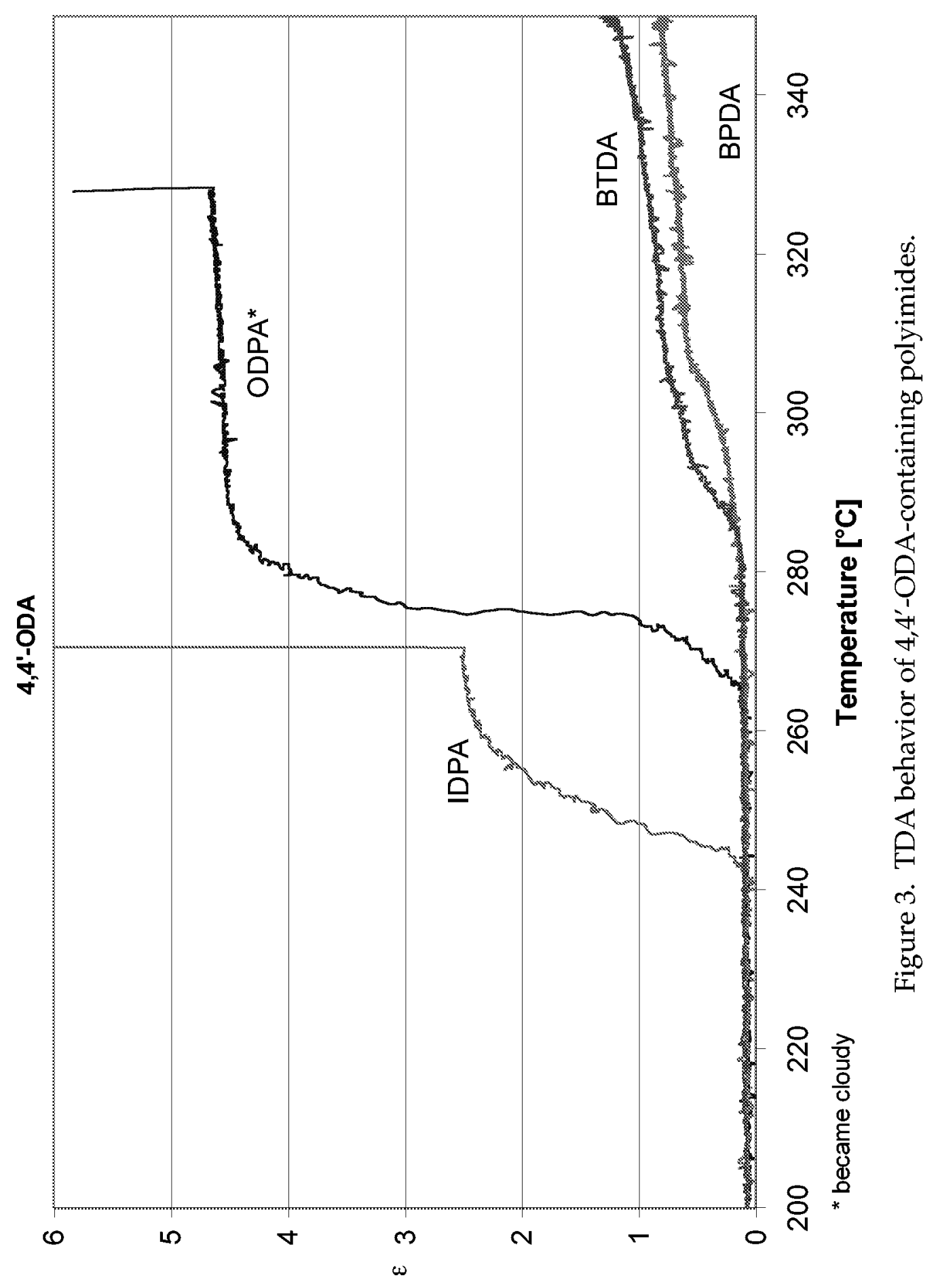




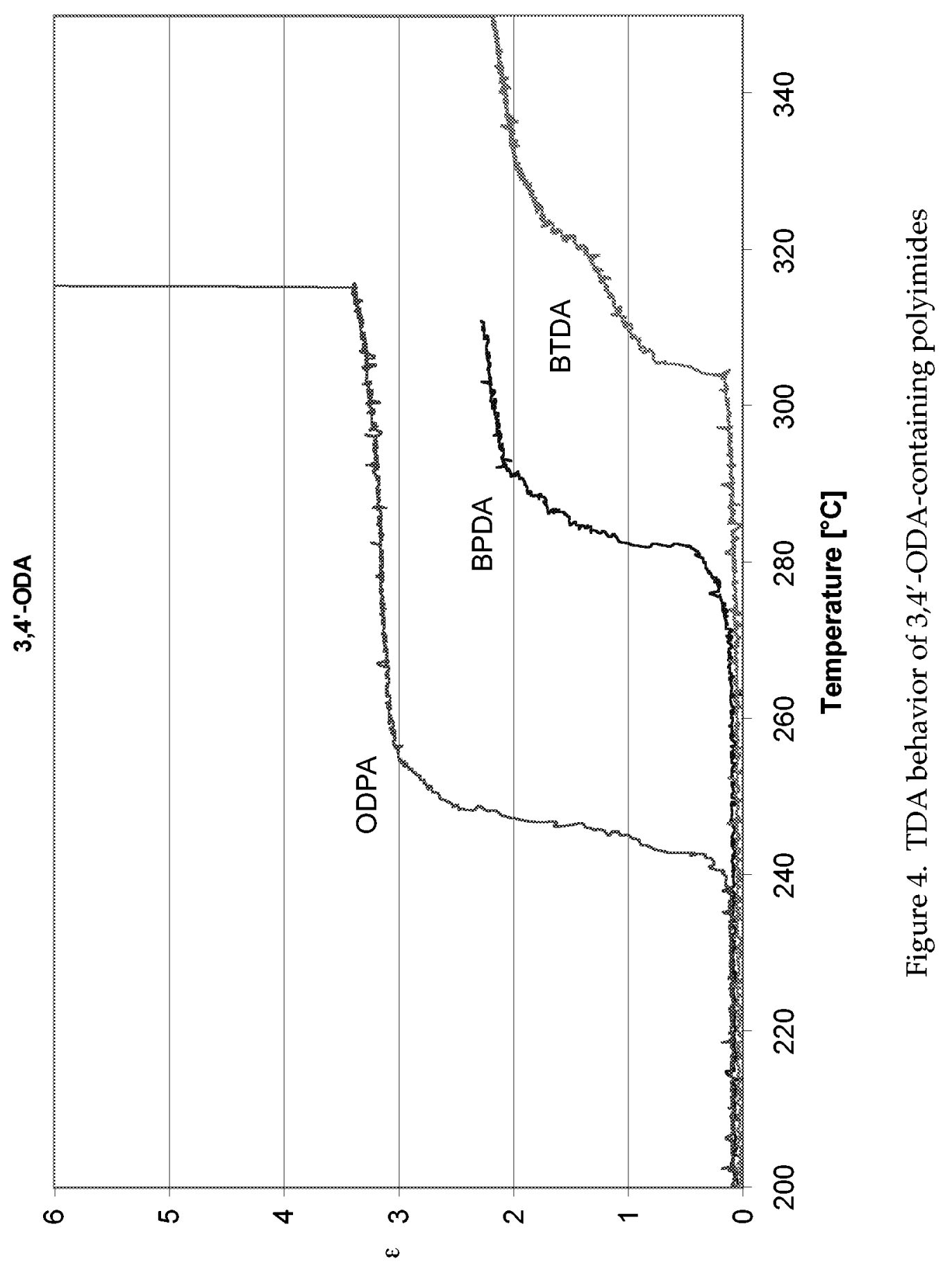




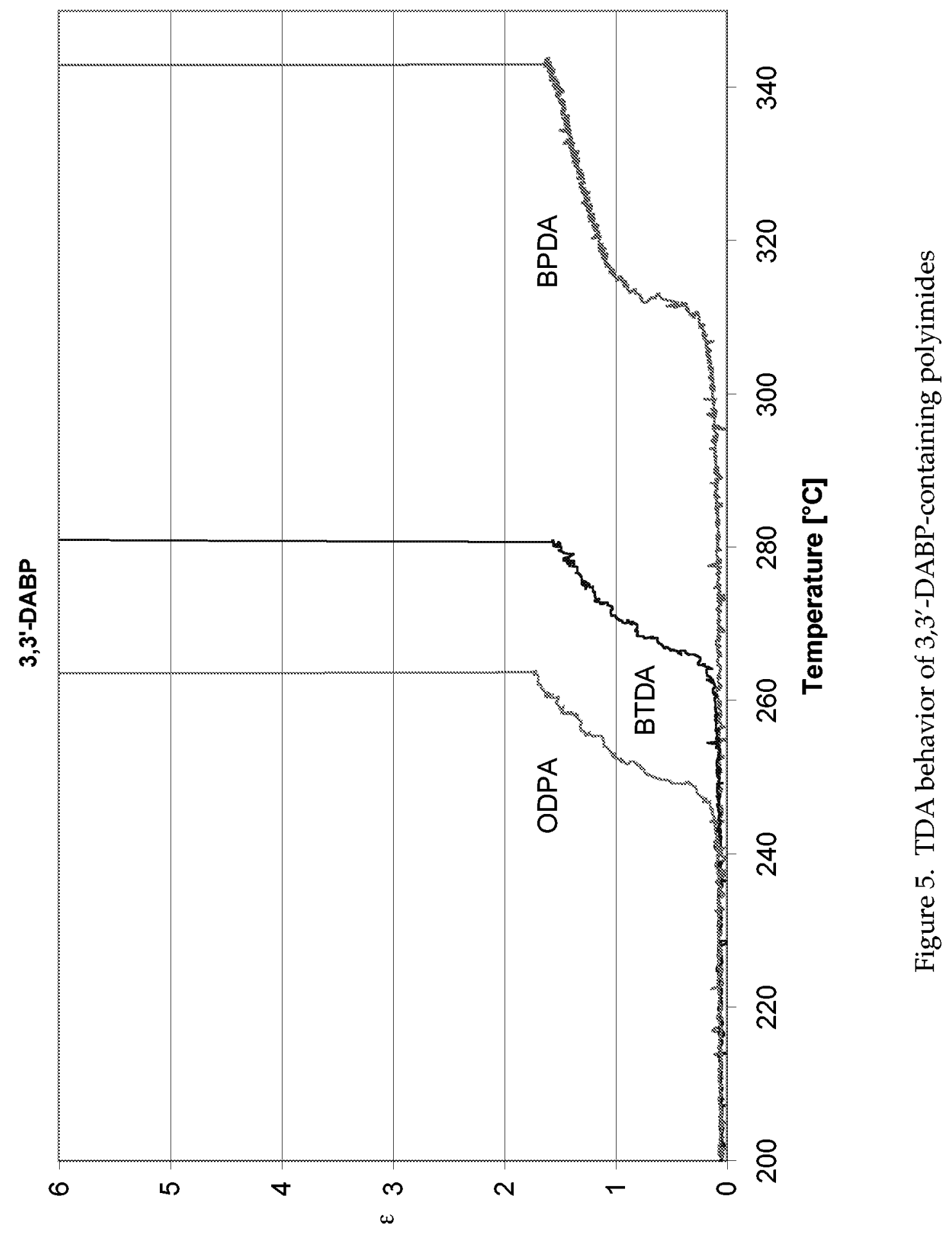




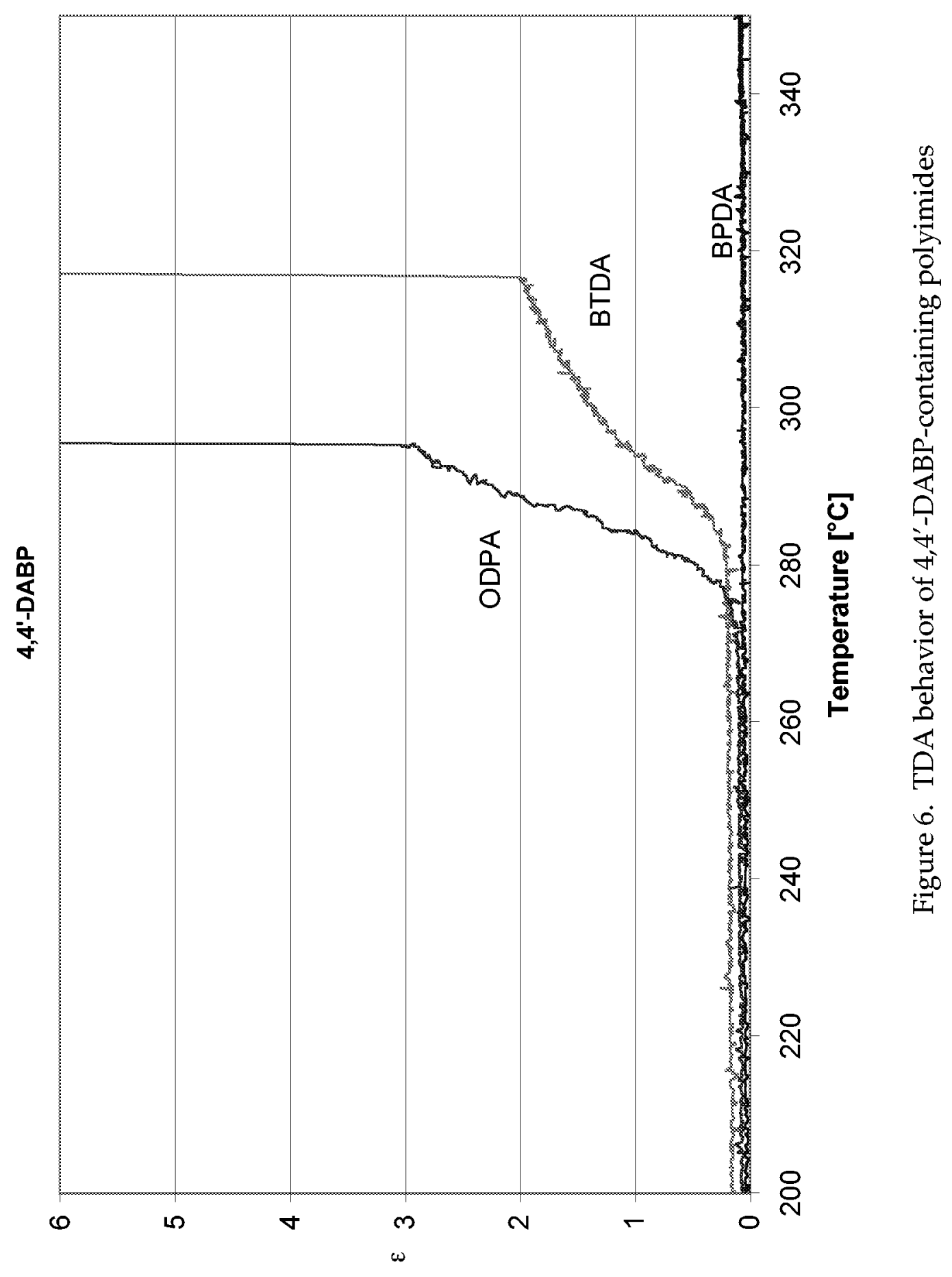




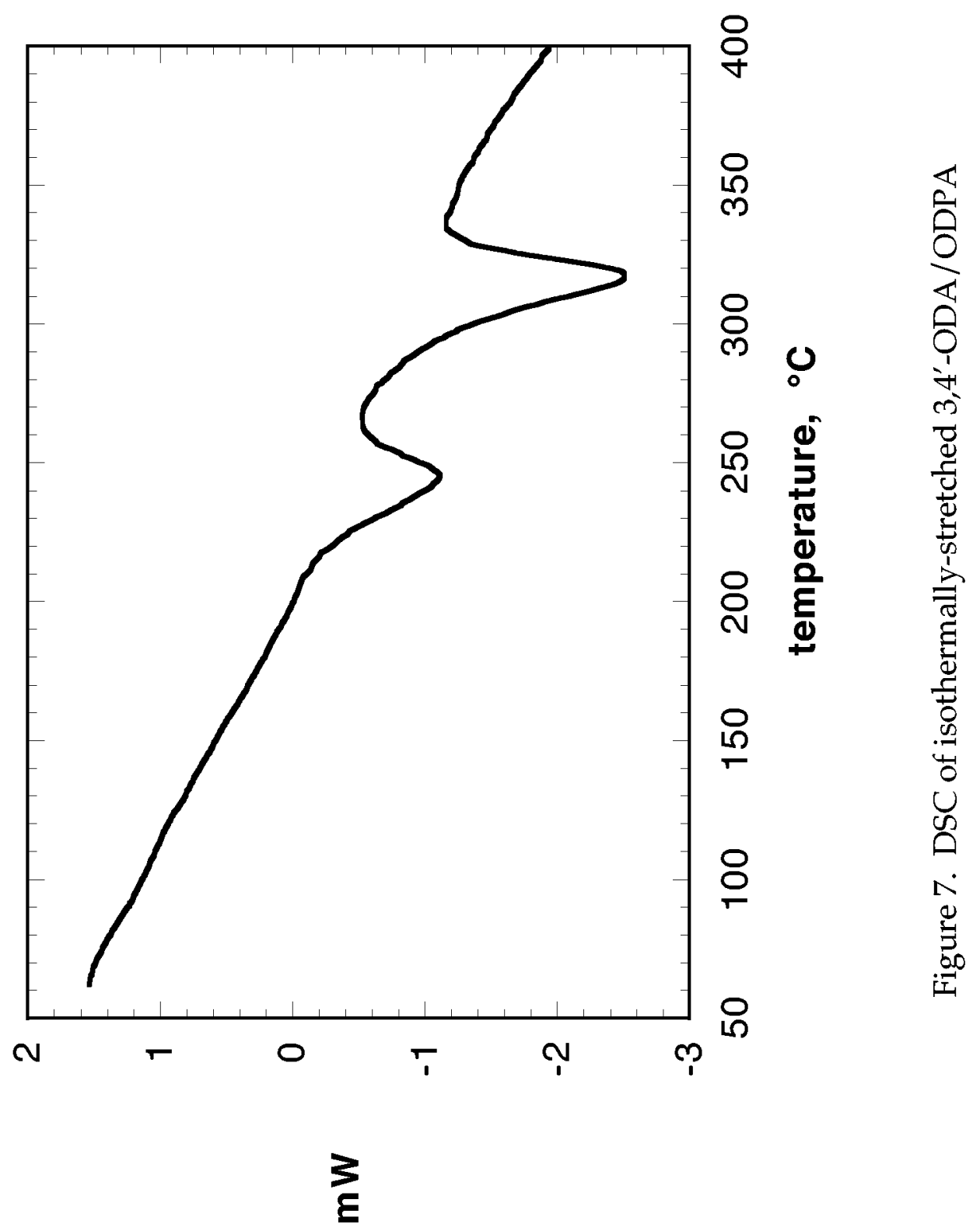




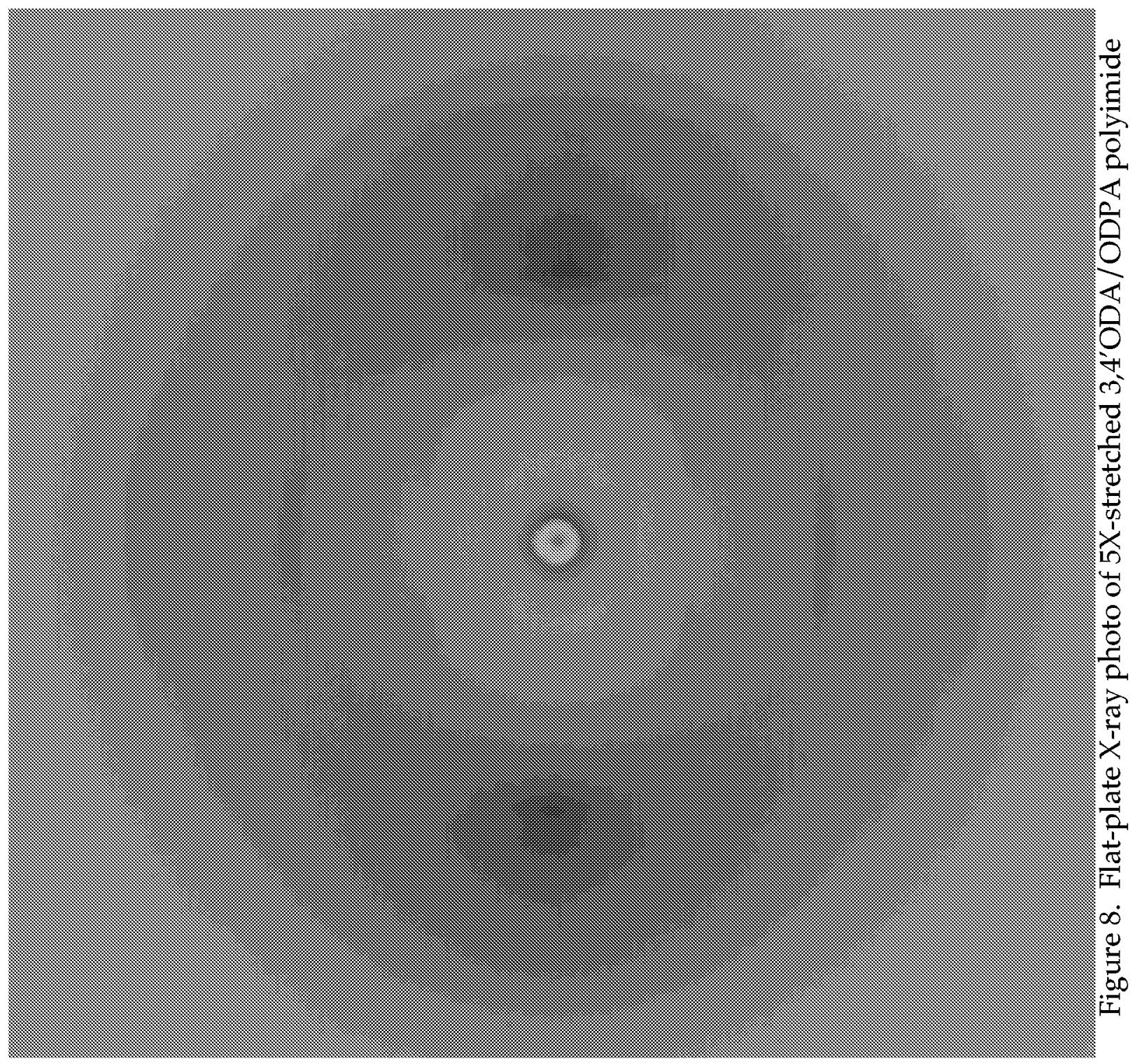




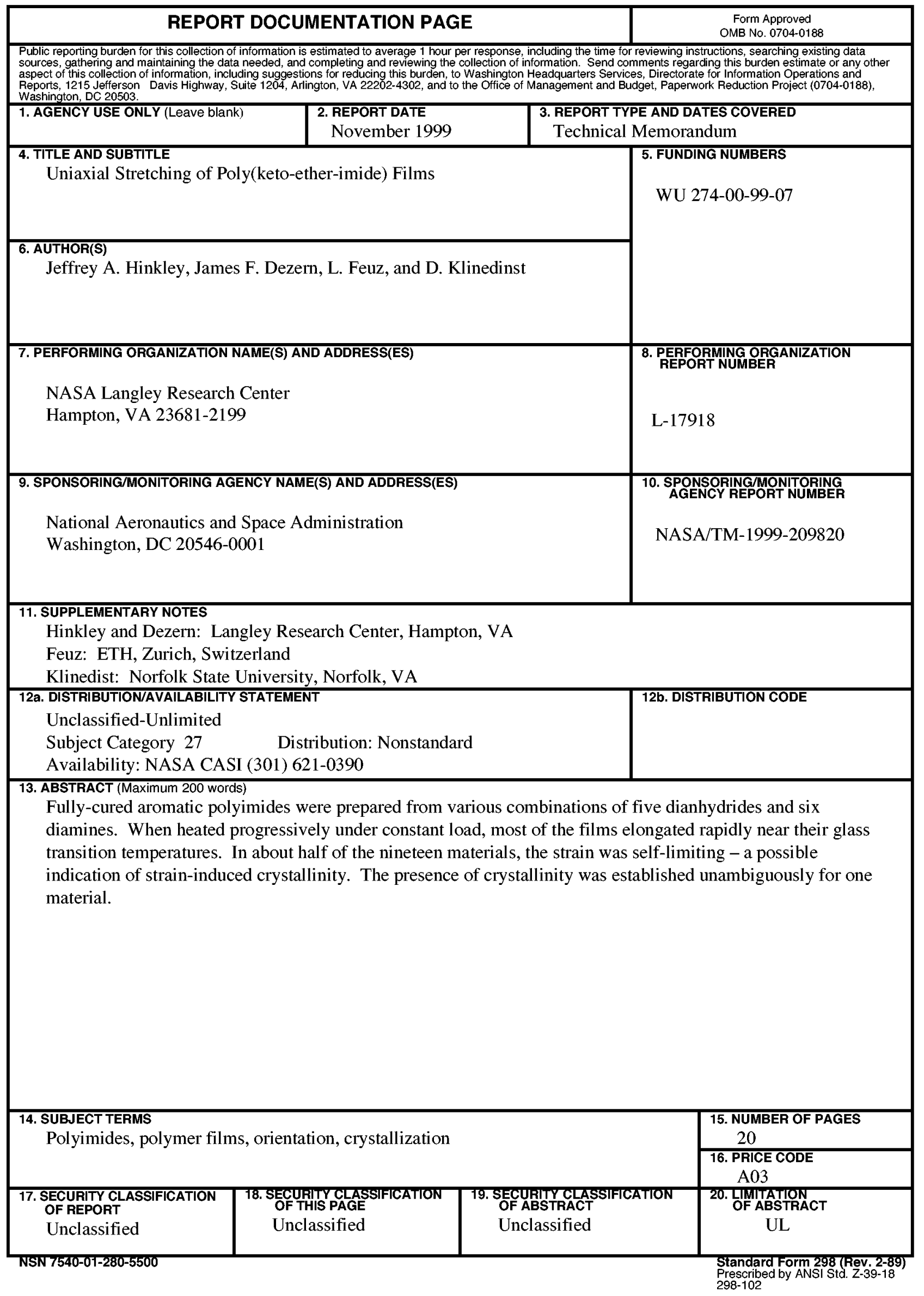

